\title{
Aa. Vv., «Ponts/Ponti, Langues, Littératures, civilisations des Pays francophones»
}

\section{Simona Rossi}

\section{Q OpenEdition}

1 Journals

\section{Edizione digitale}

URL: https://journals.openedition.org/studifrancesi/38402

DOI: 10.4000/studifrancesi.38402

ISSN: 2421-5856

\section{Editore}

Rosenberg \& Sellier

\section{Edizione cartacea}

Data di pubblicazione: 15 décembre 2004

Paginazione: 654

ISSN: 0039-2944

\section{Notizia bibliografica digitale}

Simona Rossi, «Aa. VV., «Ponts/Ponti, Langues, Littératures, civilisations des Pays francophones»»,

Studi Francesi [Online], 144 (XLVIII | III) | 2004, online dal 30 novembre 2015, consultato il 08 mai 2021 URL: http://journals.openedition.org/studifrancesi/38402; DOI: https://doi.org/10.4000/studifrancesi. 38402

Questo documento è stato generato automaticamente il 8 mai 2021.

\section{(c) $(1) \ominus$}

Studi Francesi è distribuita con Licenza Creative Commons Attribuzione - Non commerciale - Non opere derivate 4.0 Internazionale. 


\title{
Aa. Vv., «Ponts/Ponti, Langues, Littératures, civilisations des Pays francophones»
}

\author{
Simona Rossi
}

\section{NOTIZIA}

«Ponts/Ponti, Langues, Littératures, civilisations des Pays francophones», Voyages, n. 3, 2003, pp. 317.

1 Annullare distanze oceaniche, superare gli steccati della diversità, costruire arditi ponti in grado di mettere in comunicazione i paesi, le civiltà e le letterature più lontane, nel complicato mosaico dell'odierna francofonia: ecco l'obiettivo della giovanissima rivista letteraria "Ponts/Ponti". Obiettivo che peraltro sembra centrato, a giudicare dall'interesse suscitato dai primi due volumi dedicati rispettivamente a "Images infernales" (2001) e "Bestiaires" (2002). La rivista, annuale, è diretta da Liana Nissim e pubblicata con il contributo dell'Università degli Studi di Milano e del Centre culturel français della stessa città (Cisalpino-Monduzzi Editore). Si tratta di una novità editoriale importante nel panorama della francofonia, non solo italiana, grazie alla scelta di numeri tematici, alla qualità dei contributi, alla ricchezza dell'informazione bibliografica coordinata da esperti nelle varie aree del mondo francofono e anche grazie alla scelta di una struttura lineare e di facile consultazione.

2 La rivista è divisa in quattro sezioni: saggistica critica sull'argomento scelto per il numero, studi linguistici, opere inedite e note di lettura. I saggi che compongono la prima sezione affrontano il tema proposto in una prospettiva interdisciplinare e facendo intervenire le voci più diverse della francofonia, dall'Africa sub-sahariana al Québec, dalle Antille al Maghreb. La seconda sezione costituisce la parte più nuova degli studi sulle culture francofone in Italia, perché fornisce analisi e spunti di riflessione sulle varie problematiche legate alla lingua, mentre la terza propone interessanti testi 
inediti di prosa e poesia, corredati da brevi ma esaustive note introduttive. Per quanto riguarda la sezione note di lettura, essa è suddivisa in ogni volume in sette sotto-sezioni ben distinte - curate da specialisti - che coprono l'intero spettro degli studi francofoni: "Studi linguistici" (Maria Colombo Timelli); "Francofonia europea" (Rosanna Gorris Camos); "Francofonia del Maghreb" (Anna Maria Mangia); "Francofonia dell'Africa subsahariana" (Liana Nissim); "Francofonia del Québec e del Canada" (Alessandra Ferraro); "Francofonia dei Caraibi" (Marco Modenesi); infine "Opere generali"(Liana Nissim). Nel loro insieme, le note di lettura di "Ponts/Ponti" permettono a chi le consulta di seguire, in tempi rapidi, un percorso stimolante all'interno delle novità editoriali del mondo francofono.

"Voyages" è l'argomento scelto per il terzo volume della rivista. Una scelta così motivata nell'Editoriale: "puisque nous nous sommes donné la tâche de construire des ponts reliant les continents, pouvions-nous ignorer le thème du voyage? Thème universel, thème traditionnel, au centre de toutes les visions du monde et de toutes les littératures, le voyage ne cesse d'être - dans notre modernité et dans notre monde qui pourtant est devenu, en fait, un petit village global - l'un des ressorts symboliques les plus puissants" (p. 7). Per quanto riguarda l'organizzazione interna di questo terzo numero, "Ponts/Ponti" utilizza la medesima struttura a quattro spazi di cui abbiamo già parlato, ossia saggi critici, studi linguistici, inediti d'autore e note di lettura, i primi tre dei quali questa volta sono esplicitamente dedicati al viaggio. Attraverso l'opera della scrittrice quebecchese Anne Hébert, ad esempio, degli scrittori africani Mongo Beti e Tierno Monénembo, del marocchino Tahar Ben Jelloun e molti altri, si scoprono mostri e paesi immaginari, scenari da sogno e popoli fantastici; ci si stupisce di fronte alle infinite sfumature linguistiche della terminologia di viaggio; si "viaggia", letteralmente, sul treno diretto a Montréal dell'autore quebecchese Noël Audet, un treno-adolescente, che "flirta con il mare e la montagna". E per finire, il poeta valdostano Pierre Lexert ci regala incredibili aurores boréales e fiammeggianti crépuscules indiens. In questi testi, il viaggio si svela a poco a poco nei molteplici significati che nasconde: il bisogno di esperienze nuove, l'esilio, la crisi d'identità, la fuga da una società-trappola che non sa vedere oltre il filo spinato di convenzioni e perbenismo, l'esigenza e il desiderio di scoprire nuove realtà e nuovi risvolti di se stessi. È chiaro che il viaggio inteso come spostamento geografico è solo una sorta di alibi per muoversi verso dimensioni ben più importanti, quali la discesa dentro la propria interiorità, il percorso iniziatico e la rinascita. In conclusione, che sia reale o immaginario, scelto o imposto, positivo o negativo, il viaggio, come emerge dai diversi saggi che compongono il volume, resta un mezzo straordinario per mettersi in gioco ed aprirsi a mondi diversi. Ecco il punto di raccordo, dunque, il filo conduttore, il "ponte", tra il mondo della finzione e quello dei lettori, tra i tanti viaggi, letterari e non, che caratterizzano le letterature francofone. Moderna ed originale, la rivista "Ponts/Ponti" merita un posto di rilievo tra le migliori riviste specializzate in studi francofoni . 